\title{
A preliminary study on instructional design of Chinese input method for blind students
}

\author{
Jan-Li Wang • Teng-Hua Weng • \\ Sheue-Ling Hwang • Cin-Wei Huang • \\ Shwu-Ching Young
}

Received: 31 October 2014/Revised: 31 January 2015/Accepted: 4 February 2015/

Published online: 26 February 2015

(C) Beijing Normal University 2015

\begin{abstract}
Although the screen reader affords the blind to manipulate and input Chinese characters into a computer, a major problem still exists because the blind have difficulties in selecting the right character among those candidates having the same pronunciation but with different meanings. In consequence, the frequent typos shown on entering texts have hindered the readers from understanding their writing, which in turn affects their performance in school and workplace. Thus, this study aims to help blind children improve their typing accuracy from when they start learning Chinese in the elementary school. For this purpose, we first investigated a suitable Chinese typing method for the visually impaired, and then designed and constructed a self-learning instruction for blind students with assistive technology to learn an effective Chinese input method. This study was conducted in three phases:
\end{abstract}

\footnotetext{
J.-L. Wang $(\bowtie)$

National Center for High-Performance Computing, National Applied Research Laboratory, Hsinchu, Taiwan

e-mail: wangjanli@narlabs.org.tw

T.-H. Weng · S.-L. Hwang

Department of Industrial Engineering and Engineering Management, National Tsing Hua University, Hsinchu, Taiwan

e-mail: aha76540@hotmail.com.tw

S.-L. Hwang

e-mail: scy@mx.nthu.edu.tw

C.-W. Huang $\cdot$ S.-C. Young

Institute of Learning Sciences, National Tsing Hua University, Hsinchu, Taiwan

e-mail: bloodrobinx@hotmail.com

S.-C. Young

e-mail: slhwang@ie.nthu.edu.tw
} 
I. Examining a suitable Chinese typing method for the visually impaired in Taiwan; II. Designing and implementing instructional materials based on the results from phase I; and III. Evaluating the effectiveness of the course materials. Two out of the six participants completed the course training, and a six-month follow-up was conducted. It was found that the accuracy rates of Chinese character input for the two subjects were greatly enhanced in this preliminary study. The inspiring and promising results indicate that there is a need to further apply this input method to more visually impaired children in our future study. We hope more blind children can benefit from this input method and courseware through our long-term efforts.

Keywords Blind student - Chinese input method - Character identification · E-learning · NVDA

\section{Introduction}

According to Taiwan Ministry of Health and Welfare statistics (2014), there are 56,941 visually impaired people. Another statistics from the Ministry of Education for special education (2014) shows that a total of 430 visually impaired students are enrolled in Grades 1-6. Although this is a relatively small population, nevertheless, their rights for an education should be equally respected.

The screen reader affords the blind to manipulate and input Chinese characters into a computer, but the major problem still exists because they do not use an appropriate software tool under the existing instructional courseware and method to enter the text of Chinese characters. This is due partially to the loss of their eyesight as well as the lack of sufficient information in the character description, and thus causing the blind to have difficulties in selecting the right character from those candidates having the same pronunciation but different meanings. Consequently, they experience frequent typos when entering texts, making it difficult for other readers to understand their writing. This in turn affects their performance in school and workplace. Therefore, the instruction methods for the visually impaired students should be redesigned to enable them to identify and recognize characters with the most up-to-date assistive technology so that they can eventually establish a sound foundation of entering Chinese characters into a computer, raise the accuracy of their Chinese typing, and communicate with other people more effectively.

The purpose of this study is to investigate what constitute a suitable Chinese input method that has a relatively higher typing accuracy rate for the blind people and to develop course materials of Chinese input method for the younger blind students to enter texts into a computer with improved accuracy rates of typing. For the purpose of this research, the study was accomplished in three phases. In phase one, selection of a suitable Chinese input method for blind students was first investigated from different aspects. Based on the results of Phase one, the selected input method and courseware were developed in Phase two. Finally, in the Phase three, the case study courses and assessments were conducted to check if it could effectively assist the subjects to improve their accuracy rates of entering Chinese texts. 


\section{Literature review}

\section{Features of Chinese characters}

Chinese language is one of the most complicated and historic languages. "Shuowen Jiezi (說文解字), ” a dictionary that first appeared during the Han Dynasty, explains the basic principles of forming Chinese characters (Hsiao 2012). According to the Shuowen Jiezi, there are six models to create Chinese character, including pictograms, ideographic, compound ideographs, phono-semantic compounds, phonetic loan characters, and derivative cognates (Wikipedia 2014a). It points out that Chinese characters are made up of a combination of shapes (or forms), sounds, and semantics (or meanings), that, when arranged components together, form a character with a unique meaning. The characteristics of Chinese words and characters can be described as follows.

Characters are formed with components or radicals (部首或部件) which are the basic units of Chinese structure. Each component has a meaning, but the different combinations of components may form a new character and have different meanings (Jiang 2004). Some components can be seen as a single character, while others can be arranged differently to form a group of characters (Ho 2012). The same characters may have different sounds (多音字), whereas different characters may have the same sound (同音字).

Unlike other alphabetic languages where words are formed from basic elements (i.e., letters) and are written in one direction, the form of Chinese characters is multidirectional (i.e., from left to right, top to bottom, and outside to inside) (Ho 2012).

\section{Braille for blind people's reading and writing}

Braille is named after its creator, Frenchman Louis Braille, in early nineteenth century. Braille becomes an imperative tool that provides a means by which people who are blind can read and write, enabling them to become literate. Braille characters are small rectangular blocks called cells that contain tiny raised dots. The number and arrangement of these dots distinguish one character from another. The six-dot cell is commonly used all over the word. Though using the same raised dot braille, different languages may have adapted different Braille systems to represent the unique features of each language. In English Braille, it is a one-to-one transliteration of 26 letters of the alphabet, and the alphabet is the basic element of the word. Hence, using Braille, blind people are able to learn how to spell and understand words through touch which is analogous to the way sighted people learn words using their vision. This method of learning has been of great benefit to the blind for centuries, and it has been adapted for use in languages other than English.

A refreshable braille display is an electro-mechanical device for displaying braille characters, which is used to connect with a computer serving as an output device for a blind user. Normally, it uses eight-dot cells instead of six-dot cells to expand its usage, and it is called computer Braille. The development of refreshable braille display in combination of screen reader software can equips blind people to access computer more efficiently and effectively. 


\section{Braille in Taiwan for mandarin}

The concept of six-dot Braille is adapted in China, Japan, and Taiwan, but in representing the Chinese characters, called Hantz (漢字), the six-dot cell Braille system is designed to represent the phonetic element of the character, not the individual pictogram character (Murata 2004). In this situation, in Taiwan, for instance, the Taiwanese Braille is the braille script used only for Mandarin marked with Zhuyin, and even when the same Hantz is concerned, the corresponding braille used in Taiwan is completely different from that in China where the Pinyin is used to mark Chinese characters. Moreover, ambiguities may occur in those characters which are pronounced the same and have identical representing Braille, thus making it difficult for blind Braille users to distinguish the differences among these characters. As an extreme example, there are a total of 207 Chinese characters pronouncing the same sound of "Yi" in Mandarin, yet each of these characters has its own meanings, which makes it rather difficult and time-consuming to select the desired one when using Zhuyin input method. Also, the use of refreshable braille displayed as mentioned above does not actually provide any clue for the learner in Chinese character recognition because of it displaying only the sound message. Hence, it is quite common for the blind to neglect the learning of characters identification and recognition (Chuang 2004).

All students, including the blind students, in Taiwan are taught with Zhuyin to assist the learning of the Chinese characters from the very beginning of elementary school. The blind students must also learn Taiwanese Braille for Mandarin, and the Braille cells are designed to represent the Zhuyin symbols of the Chinese characters except that there are 22 extra combination cells which allow putting two vowels of Zhuyin symbols together to form a single cell, such as the Chinese character "wang" (汪) being represented with single braille cell, not two cells. In this situation, it is not difficult for blind students to learn Taiwanese braille for mandarin, and it also does not take much extra effort for them to learn the Zhuyin input method on a computer. However, blind students are taught using Braille input, not the standard keyboard input, which in combination with the deviation of Taiwanese Braille from the normal Zhuyin as mentioned above may result in the difficulty for them to adjust their typing habits after they are getting grown up (Wang et al. 2014).

In summary, the entry level of learning Zhuyin input method for blind students is relatively low, but too many typos in the typing documents continue existing in their lifelong career and have negative effects on their Pursuing for higher education and professional job. It is imperative to teach the blind youngsters with a complete different approach of typing Chinese characters into a computer at early stage in elementary school.

\section{Character identification and recognition}

Chinese is a pictogram language that implies visual messages. Therefore, understanding the words' or characters' basic structure is imperative in learning Chinese (Kwok \& Chan 2008). Hsiao (2012) conducted a study for teaching and 
evaluating a congenitally blind individual to learn and write 48 characters. She found that tactile Chinese character instruction (TCCI) had an immediate and maintaining effect on improving the performance of character recognition for the subject.

However, it would be a heavy burden, if not impossible, for the learner to remember the all tactile Chinese characters once the number is increased up to about 2700 Chinese characters as defined by Taiwan Ministry of Education for elementary students to recognize. Therefore, when constructing the instructional design, considerations should be taken to resolve this issue with the fully use of the assistive tools.

\section{Chinese input method}

Unlike the single universal way to input alphabets into a computer, the countries that use Chinese characters or Hantz, such as China, Japan, and Taiwan, have developed their own input methods depending on their language learning policies in their education systems.

There are many different means of entering texts into a computer such as typing, handwriting, and speech to text (STT). In considerations of accuracy, typo correction, popularity, and efficiency, only the keyboard input (typing) is considered for this study. According to Longcamp et al. (2006), the mechanism in human processing typing behavior acquires less special knowledge and memorizing less information of a character, which matches the need for the subjects in the present study.

The Chinese character input method used in Taiwan can be further categorized into either phonetics-based such as Zhuyin (注音) and Going (自然), or shape-based such as Boshiamy (唖蝦米), Cangjie (倉頴), and Da Yi (大易). According to the Pollster survey conducted in 2011 (Pollster 2011), more than $70 \%$ of people living in Taiwan use the phonetics-based input methods (including New Zhu Yin $49 \%$, Zhu Yin $22 \%$, and Going $3 \%$ ) to input Chinese characters, as well as 10.7, 9.9, and $3 \%$ use Boshiamy, Cangjie, and $\mathrm{Da} \mathrm{Yi}$, respectively. The most popular input methods used in Taiwan are further described as follows.

Zhuyin is originally used to mark the pronunciation of Chinese characters for Mandarin and is developed to become an input method for entering Chinese characters into a computer. When using the Zhuyin-based input method, the user enters the pronunciation of a character, which is converted into a list of homophones, and then the user must select the desired character from the list of homophones, which are considered as the candidates for that character. Although there are many drawbacks of using phonetics-based input method, such as not efficient and only valid for those characters pronouncing correctly in Mandarin, it remains the predominant phonetic system in teaching reading and writing in elementary school in Taiwan. It is also one of the most popular ways to enter Chinese characters into computers and to look up characters in a dictionary in Taiwan. To improve the typing efficiency, Microsoft has developed New Zhuyin input method with the function of predict the desired characters based on context 
and user preferences, and the input method with this kind of function is called smart input method. The commercial input method, Going is also one of the smart input methods, while the Zhuyin has no such kind of function. However, using this kind of phonetic-based input methods, blind users cannot distinguish among those candidates as they all sound the same. Therefore it is necessary for the assistive tool to provide the function of navigating individually the candidate list to gain more information such as character description for the blind user.

Cangjie was invented in 1976 by Chu Bong-Foo. Unlike Zhuyin, Cangjie is a completely shape-based input method (Wikipedia 2014b). The basic character components representing a graphical unit in Cangjie are called "radicals" (字根) which are similar to "letters" in English. There are 24 (not 26) in all, each radical is mapped to a particular letter key on a standard QWERTY keyboard. Additionally, "difficult character" function is mapped to the X key. The 24 basic shapes are associated with roughly 76 auxiliary shapes which in many cases are either rotated or transposed versions of the basic components (Wikipedia 2014c). Learners need to remember the layout of each radical and its associated auxiliary shapes on the keyboard, and it would be difficult for the learner who has completely no idea about the shape of Chinese characters. Cangjie is a free and open source and can be downloaded directly from Microsoft Windows operation system.

Boshiamy was invented by Liu Chung-tz'u in 1989. It is not a purely shape based, but a hybrid input method. There are about 300 Chinese radicals (字根) used, which are mapped to 26 letters by the concept of forms (形), sounds (音), or meanings (義) (Wikipedia 2014d). A letter representing a radical in Boshiamy is called a code (字根碼). Since the radicals in Boshiamy are directly mapped to letters on the keyboard, unlike “乌文 $\rceil$ ” in Zhuyin and “金木水火土” in Cangjie, there is no need for learners to remember another corresponding relationship between the code of radicals in Boshiamy and keystroke layout. Boshiamy is not a free open tool, but commercial software.

\section{NVDA screen reader}

A screen reader is computer software that attempts to verbally identify and interpret what is being displayed on the screen. This interpretation is then represented to the user with text-to-speech (TTS), or a Braille output device. Screen readers are assistive tools, which are useful to people who are visually impaired when using a computer. The invention of computers and the development of technologies have been drastically changing the way how people learn and access information (Marcia et al. 1999), and screen readers enable those visually impaired to manipulate a computer, which bridges the digital divide.

Non-visual desktop access (NVDA), the screen reader, has been developed by Michael Curran and James Teh since 2006, and has been proven to be compatible to many current softwares in Microsoft Windows operation system (Leahy \& Lawler, 2012). NVDA is free open software which is available for everyone to use in more than 40 languages, including traditional Chinese. It is estimated that there are about 
fifteen hundreds users in Taiwan, which makes NVDA one of the top two screen readers.

NVDA provides the function of keyboard help, which enables a blind beginner to learn the name of each keystroke by him or herself. Also, the function of character description enables users to know the meaning of the Chinese character timely under the cursor, which is useful when entering the text into a computer. Wang et al. (2011) suggested that the blind students could break the dilemma of inaccessible to information by effectively using NVDA screen reader.

\section{Research framework}

The framework of this study is shown in Fig. 1 flowchart of research method. It is divided into three phases in this study including selecting one input method, developing digital learning system of the selected input method as well as conducting a case study courses and evaluation. The tasks involved in each phase are described in the following:

Phase I: selection of input method

To decide which Chinese input method is suitable for blind students to enter texts into a computer, three activities include "Typing accuracy test," "Survey of questionnaire," and "Interview," which are further described as follows.

\section{Typing accuracy test}

This activity is to compare the typing accuracy among the selected input methods, and it is designed to reflect their default functions, independent of the person who does the typing tests.

First, two articles including one classical and one vernacular are selected from the textbook of secondary level education, and then the contexts of the two articles used as

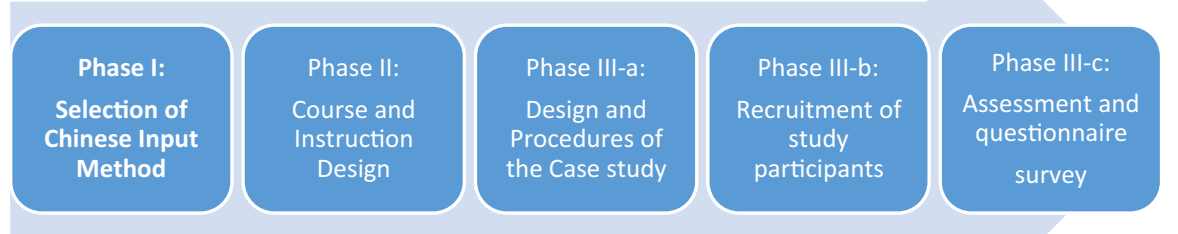

Fig. 1 Flowchart of research method 
the typing texts. The context of vernacular article "The Blue Bird is right beside you" (青鳥就在身邊) represents the average level for people with secondary level education, while the context of classical article "The Commonwealth of Great Unity" (禮運大同篇) represents the advanced level. The top two commonly used phoneticbased Chinese input methods including Microsoft New Zhuyin (新注音) and New Going (新自然) are separately conducted in the typing of the text under the conditions that each character was pronounced and typed correctly by one sighted researcher of this team, as well as complete with no selection from the candidates list. The assumed condition tested typing without selecting the desired character from the candidate list. This generally reflects the majority of the congenitally blind students when they are entering texts into a computer. The two shape-based input methods including Boshiamy (舆蝦米) and Cangjie (倉頡) also follow the same process by another sighted people for the typing test, and their accuracy rate is only for reference. This is because in normal process of entering text, the typist of both methods, not like the phonetic-based typist, can distinguish and select the desired character from the candidate list, if necessary, without difficulty. The typing results for each input method are used to calculate their accuracy rates.

The tests were conducted on a personal computer, and before each test for one input method starts, the input method used is restored to the initial default state to erase the previously built-up phrases which may influence the test results.

\section{Survey of questionnaire}

In order to survey the satisfaction of using input methods for the visually impaired, the questionnaire was designed to have two parts; first part is related to background information, including age, education, keyboard layout, Chinese input methods, years of experience, and the screen reader. Second part is about investigating the satisfaction level of using the input method. There are eight items, including: Ease of learning, ease of using, ease of selecting from candidate list, frustration of typing, customization, typing speed, accuracy, and willing of skill improvement. The questionnaire is designed based on the concept of NASA-TLX and is written in Chinese, and is translated into English as shown in Appendix 1 Survey of questionnaire for the satisfaction of using Chinese input methods.

Questionnaire was sent out with an e-mail to a mailing list of about 150 visually impaired people (VIP) targeting those living in Taiwan, and the e-mail receivers were encouraged to forward to their VIP friends to get more respondents. Respondents could either reply back via e-mail directly, or filled out questionnaire on a web site which could automatically collect the data online. The Likert 5-point scale was used in the Questionnaire, and each question had five levels of satisfaction, which were from strongly satisfied (5) to strongly unsatisfied (1).

\section{Interview}

The semi-structured and in-depth interview was conducted individually face-to-face with prepared outline of questions in this study. We interviewed two knowledge 
Table 1 Comparisons on accuracy rates of four different input methods used in Taiwan

\begin{tabular}{lllll}
\hline Input methods & Article type & $\begin{array}{l}\text { Words } \\
\text { count }\end{array}$ & $\begin{array}{l}\text { Typos } \\
\text { count }\end{array}$ & $\begin{array}{l}\text { Accuracy } \\
\text { rate (\%) }\end{array}$ \\
\hline New Zhuyin (新注音) & Vernacular (白話文) & 508 & 31 & 93.9 \\
& Classical (文言文) & 129 & 25 & 80.7 \\
New Going (新自然) & Vernacular (白話文) & 508 & 55 & 89.2 \\
& Classical (文言文) & 129 & 26 & 79.9 \\
Boshiamy (嘸蝦米) & Vernacular (白話文) & 508 & 9 & 98.3 \\
& Classical (文言文) & 129 & 3 & 97.7 \\
New Cangjie (新倉頍) & Vernacular (白話文) & 508 & 0 & 100 \\
& Classical (文言文) & 129 & 0 & 100 \\
\hline
\end{tabular}

workers with congenital blindness. Questions covering those issues related with working experience, assistive tools, and input method used. The interviews were focused on realizing what they had suffered from the problem of typo issue on their jobs. At the end of interview, final question was raised about what they would suggest for those potential blind knowledge workers in selecting the Chinese input method.

Results and discussion of Phase I (selection of input method)

\section{Test of input methods}

After typing the two kinds of articles (vernacular and classical) with the selected four input methods, the typing outcomes are counted manually on the number of character being typed and number of typos. The test results of the accuracy rates for the two phonetic-based and two shape-based input methods are listed in Table 1 for comparison.

As shown in Table 1, the higher typing accuracy rates of two phonetic based are the New Zhuyin, at only $93.9 \%$ for the vernacular texts and $80.7 \%$ for the classic texts, which are normally not an acceptable accuracy rate for those documents on office work. Although modern phonetic-based input methods all claimed to have smart design that can predict the desired characters based on context and user preferences, it still requires people typing to visually pay attention to check and choose the desired characters from homophones. For example, when typing the string “企求原諒," “企求” and “汔球”, both are homophones, and then the third character “球” is typed, which forms another “球員," then the input system has to predict and decide which is the desired one. Normally, without immediate check with attention, the typos are generated, which is in general the most difficult issue that blind users face.

In comparison, for the shape-based input method, the accuracy rate for New Cangjie is $100 \%$ for both articles, and the accuracy rates for Boshiamy are about $98 \%$. Further examining the difference of this, it is found that the New Cangjie has a smart design, yet Boshiamy, to predict the desired character based on context, while typos in 
this test may occur for using Boshiamy are those characters that have duplicate codes (重碼字), such as “已” and “已”, under the assumed condition that no action is taken to choose the desired one when entering texts. However, this is not the real case for those Boshiamy users, because they can immediately distinguish the different pronunciations of the duplicate codes from the feedback voice.

\section{Survey of questionnaire}

There were 33 respondents (collecting from google forms-create and analyze surveys, for free) during the one-week period of survey. After screening out four invalid questionnaires, there were 29 effective questionnaires. Among these, there were 13 Zhuyin users (including New Zhuyin and New Going), 10 Boshiamy users, and 4 Cangjie users. The ages of respondents range from 8 to 60 and the years of experience using input method are all more than 1 year.

In this study, the Likert five-point scale was used, and each question has five levels of satisfaction, which are from strongly satisfied to strongly unsatisfied, with the scores ranging from 5 to 1 points. The higher score represents the higher agreement on level of satisfaction. Based on the input methods used, the results are classified into three groups including Zhuyin, Boshiamy, and Cangjie. The results of each item of second part in the questionnaire were calculated. The arithmetic's averages were calculated for each group, and the results are shown in Table 2.

From the results of this survey, it is found that the overall satisfaction levels of both Zhuyin (ranging from 2.6 to 3.5 , and their corresponding standard deviation (SD) ranging from 0.5 to 1.1 ) and Canjie (2.8 to 4.0, S.d. ranging from 0.44 to 1.1 ) input methods used by the population are generally lower than that of Boshiamy (3.6 to 4.5 , S.d. ranging from 0.92 to 1.26 ) user population. While on the typing accuracy rate, the satisfaction level of Zhuyin is the lowest (only 2.6) as compared with the other two, Boshiamy (4.4) and Canjie (4.3). The last item of questionnaire is to check if the visually impaired population is willing to learn skill for improvement on typing, and it reflects high correlation with the satisfaction level of those previous items for the Zhuyin user's population, which is the highest (4.2) among the three input methods.

Table 2 Survey of using Chinese input method for the visually impaired in Taiwan

\begin{tabular}{llll}
\hline Items & \multicolumn{2}{l}{ Input method types } & Cangjie \\
\cline { 2 - 4 } & Zhuyin & Boshiamy & 3.3 \\
\hline Easiness of learning & 3.5 & 4.5 & 3.3 \\
Easiness of using & 3.5 & 4.4 & 3.0 \\
Easiness of selecting from candidates list & 3.0 & 4.1 & 3.5 \\
Frustration & 3.3 & 4.2 & 2.8 \\
Customization & 2.6 & 3.6 & 3.0 \\
Speed & 3.2 & 4.0 & 4.3 \\
Accuracy rate & 2.6 & 4.4 & 3.8 \\
Willing of skill improvement & 4.2 & 4.0 & \\
\hline
\end{tabular}




\section{Interview}

Two knowledge workers one is an official of a local county government at age of 27 and another is an attorney of a not-for-profit foundation at age of 35 . Both were interviewed in this study, and both were taught to use Zhuyin input method with Braille keyboard layout from the beginning of using computer.

(1) In the working experience aspect, both interviewees emphasized and agreed the importance of the accuracy in typing for their office work, especially to build up the sense of profession and improve work independence in job career. One interviewee indicated "Lots of typos in my typing documents really made people doubt my profession, and it also took me much time to explain both to the readers including my boss." "In many cases, I have to ask somebody to do proofreading on my typing materials. If it is a formal document."

(2) In the assistive technology aspect, they had been trained how to use the computer with assistive tools. They expressed their thoughts that the invention and development of computers and other equipment like refreshable braille display, could be useful for them to learn those things that were thought impossible for the congenitally blind in the past. One mentioned that "By using the "blind" computer or other assistive tools, I can get an immediate feedback. The information interaction becomes bidirectional." "Although I cannot see, I can still hear. If there is a method assisting me to access the information completely, I believed I can work on it."

At the end of interview, both strongly suggested for the blind to learn the shapebased input methods such as Boshiamy and Cangjie in the early stage of school.

In summary, based on the above results and discussions including interviews of the blind knowledge workers, survey of visually impaired people on input method, and typing tests of different input methods in this study, both Changjie and Boshiamy input method present far better accuracy rates over phonetic-based input methods with smart function. It is found that the data base of Chinese character for Changjie is completely based on the shape of Chinese characters after further investigation, which is impractical for congenital blind to learn.

On the other hand, Boshiamy with its special features of handling Chinese character database presents in all aspects that it is a potential and suitable input method for the blind to resolve their typing problem encountered in school and on job. To further support this finding, it is necessary for us to construct a digital learning system for blind students to learn Boshiamy input method and conduct experimental instruction courses.

\section{Phase II: instruction design}

After the investigation in the first phase of this study, the suitable input method (Boshiamy) was selected to serve as the input method for the subjects in the following phase. The course and instruction material were designed in the essence of non-visual sensory learning. The concept of design is described as follows: 


\section{Composition of Chinese character}

The principles of the formation for Chinese characters, i.e., liùshū (六書), is first introduced to the learners, and then basic strokes such as horizontal line (橫), vertical line (豎), stroke to the left (粘), and stroke to the right (捺) were taught. In this course, how to write the exact strokes of a character as sighted people was not the key point, but the learner must learn how to describe a Chinese character in radicals and to understand when a person verbally described a new character to him or her. For example, three horizontal lines and one vertical line form the character king (三橫一 豎王), as well as tree and son form the character of surname Lee (木子李).

Then the Chinese characters of various types of structures were used to learn how different characters were formed. The Chinese stem-deriving instruction method was also used. We also taught the learners how to combine those known components into new one.

\section{Tactile Chinese characters}

The basic components of Chinese characters, that being, in most cases, less than six strokes were printed in tactile format (some examples are shown in Appendix 2 Examples of Tactile pictogram materials), which were used for the learners to develop the mental image of the pictogram character. There were 98 tactile characters in total used in this study. Tactile character material was designed. Each page included six $7 \mathrm{~cm} \times 7 \mathrm{~cm}$ components, or characters, with a height no less than $0.5 \mathrm{~mm}$ according to the tactile study proposed by Edman (1992).

Subjects were encouraged to read out each stroke when they were using their fingers to touch a tactile character such that the memory of multi-sensory stimulation was enhanced, especially for the last stroke which was important to the rule of Boshiamy input method.

\section{Boshiamy input method}

To learn Boshiamy input method, the instruction strategies are as follows:

1. Familiar with each keystroke in a QWERTY keyboard: Boshiamy uses about 300 radicals represented by 26 letters to build Chinese characters. It was necessary for subjects familiar with each keystroke before beginning of the instruction courses.

2. Learn the method of Pinyin: there are more than half of radicals which are sound based and are mapped to letters like Pinyin, which is an easier way to start. For example, the character 粉 is decoded as MBD, which respectively corresponds to the radicals 米 (Mì), 八 (Bā), and 刀 (dāo).

3. Learn radicals mapping to codes from simple to complex: radicals with less than six strokes with the tactile pictograms were used to learn first simultaneously such that the concept of adding a Supplementary code to a radical is enhanced. Then, those radicals with more than six strokes were learned following the same way except no tactile pictograms provided. Subjects were encouraged entering the 
texts into a computer with the voice feedback by NVDA screen reader when they were learning. Follow the pace as beginners learning in elementary school: radicals covering 300 characters were selected from the textbook of Chinese course from Grade 1 to 6, and then the number was increased to 500, and step-bystep up to about 2700 characters which was defined by the Ministry of Education, Taiwan, for the level of Grade 6 students. Although remembering that all radicals of Boshiamy could increase the typing efficiency, considerations should be taken to prevent heavy mental workload on the subjects.

4. Remember the radicals with mnemonic tricks: view those radicals alike of Boshiamy categories in a group, not by individual. For example, “央” (meaning “central") and “史” (meaning "history") are based on the character “中” (meaning "mid"), and they all use letter " $\mathrm{C}$ " to represent this group of radicals.

\section{Instructional material}

The instruction materials were designed to cover topics as follows:

1. Ch. 1 basic operations of NVDA those basic operations associated with the Boshiamy input method included voice feedback of keyboard help and character descriptions are covered. Some examples of characters descriptions in NVDA are shown in "Appendix 3 examples of character descriptions in NVDA file for traditional Chinese" section.

2. Ch. 2 typing skills typing letters on the keyboard with right fingers was introduced.

3. Ch. 3 formation of characters basic strokes, composition, and different structure types of Chinese characters were covered. Some examples for the formation of characters are shown in "Appendix 4 some examples of commonly used Chinese Characters for Boshiamy File" section.

4. Ch. 4 tactile characters skills of "listening to"(疅) how the stroke order of a character was described orally, of “reading”(讀) by fingers touching the tactile characters, of “speaking”(說) the stroke order, and of “writing”(寫) on a Braille-writing board are covered.

5. Ch. 5 categories of radicals understand the concept of correspondence between the radicals (部件) in Chinese characters and Boshiamy radicals (字根) which were mapped to letters in keyboard. Numbers from one to ten in Chinese 一 to 十 character (not Arabic numbers) were first introduced, which could be found as one single-radical or part of multiple-radical character in many Chinese characters.

6. Ch. 6 rules of character input learn to use the sequence of decoding or root taken (拆碼). Normally, it followed stroke order of a Chinese character such as left-to-right, top-to-bottom, and outer-to-inner. Taking the character 明 (meaning "bright") for example, the left part was taken first, and then the right. Some exceptions deviated from normal stroke order which needed to pay attention were also included in this Chapter.

7. Ch. 7 supplementary rules learn to apply the 11 different types of shapes to add the last stoke of the character which contains one or two radicals. 
8. Ch. 8 Query of help issues such as unknown the decoding codes of a character, punctuation symbols, selection of candidates, and shortening of code etc were covered.

This study started with 300 of the most commonly used characters in the junior level of the elementary school, which were considered as the first learning targets.

Phase III-a: design and procedures of case study

\section{Conducting the case study courses}

(1) Day 1 the first four chapters were covered.

(2) Day 2 Chap. 5 and Chap. 6 were covered.

(3) Day 3 The last two Chapters and overall review were covered.

\section{Assessment}

The assessment included two parts, which were typing tests and mental work load assessments, and both were conducted before the quasi-experimental courses were given. The results were considered as the baseline data. The courses proceeded, and four typing tests were conducted to record the progress of the subjects. After the courses ended, both typing test and mental workload were conducted again for comparisons. The assessments of subjects were compared individually with the subject itself, not among the group.

The methods employed for assessment are described as follows:

\section{Typing test}

In order to design the proper difficulty level for the subjects, two elementary schools teachers were invited to check if the typing materials were proper for the purpose of this case study.

For the contents of each quiz, characters were randomly picked up from the character database and composed to form phrases or sentences. Each quiz was set for $5 \mathrm{~min}$. The reading out speed was set for 140 characters per minute, but the person taking the quiz could adjust by himself and paused anytime during the quiz.

The subjects were asked to fill in the NASA-TLX (2003) questionnaires about using their original method and using the Boshiamy input method in the last course. Interviews were adopted to investigate the participants' study experiences before and after the instruction.

Phase III-b: recruitment of participants

The blind students who met the following criteria were invited to participate in this study: 
(1) Ministry of Health and Welfare, Taiwan (2014), blindness was defined as the disabled of visual organs (optic nerve or visual center of brain) due to congenital or acquired impairment and had difficulties to identify external things even after the medical treatment.

(2) Should not be able to identify the details of Chinese characters even with the magnifying assistive tools.

(3) Should have very fuzzy or no shape image on Chinese characters. Had a strong motivation to learn, and wanted to improve Chinese input accuracy and speed, and promised to complete the assigned work in accordance with course planning.

(4) In order to achieve learning outcomes, participants must have a sighted partner to accompany the participant and learn the input method together.

Initially, there were six subjects, three elementary students and three adults were selected to participate in the case study instructional courses. Two subjects are, respectively, in the first grade and the second grade in the normal elementary school. They just begin to learn Chinese characters as the sighted ones. One subject is in the fifth grade in the elementary school, who is born with low vision (0.03) and able to recognize and learn words using magnifying tools. With hard efforts, one subject is studying in university with right ear impaired. Two subjects graduated from university and now are working as the customer service and computer teacher. The adults lacking the concept of Chinese component structures can only write down their names and few words.

Phase III-c: assessment and mental loading survey

Before the formal instruction, the subjects went through an assessment of entering texts using their familiarized input method with IQ-Chinese Quiz software, which was set as the baseline of the case study, and each subject had taken four times of assessments in total during this.

The score counting of the quiz followed the rules of TQC. After the end of the last typing assessment, subjects were also asked to complete an NASA-TLX questionnaire for measuring their mental workload. The results were used to evaluate mental workload for cumulative learning effect between using original input method and using Boshiamy. These scores were counted from the average of six subscales without concerning pairwise comparison, which could actually increase validity and reduce errors (Bustamante \& Spain 2008).

Results and discussion of phase III: case study courses evaluation

The instruction was carried out in the National Library of Public Information where the equipment was located. A total of three courses were held during the period of October till December 2013. There were 6 hours for each day's course.

Although there were six subjects in the beginning of the instruction, only two of them had followed the complete instruction and was willing to accept performance assessment. The parameter sets for the test were $5 \mathrm{~min}$ of test time and 140 
characters per minute of reading speed allowing for pauses in-between each sentence.

\section{Subject $A$}

Subject A is in the fifth grade in the elementary school. He was born with low vision (0.03) and is still able to recognize and learn words and their strokes using magnifying tools. Until attending this program, he was not familiar with the English standard keyboard layout. Thus, his typing was slow and contained many mistakes because he had few opportunities to use this layout in his daily life. His residual vision probably gave him an advantage in recognizing and decoding characters.

The result indicated that he had great improvement since the last time (Table 3). Although he had knowledge of characters due to his visual aid, he was not familiar with the layout of the English keyboard, which had influenced his typing speed before. With continued practicing and becoming more familiar with the new method within 4 months, he reduced the number of typos and his typing speed of Boshiamy surpassed his original method (New Zhuyin).

\section{Subject B}

Subject B is in the second grade in the elementary school. He is a congenital blind, and he had learned the NVDA. The result indicated that subject B became accustomed to the operation mode with Boshiamy and NVDA. His typing speed through Boshiamy nearly reached his speed with the original method, and the accuracy of his typing improved (Table 4).

In the self-evaluation perspective, the participants would evaluate their performance with considering their learning situation at home. Subject A and subject B

Table 3 Subject A's typing performance

\begin{tabular}{|c|c|c|c|c|c|c|}
\hline & \multirow{2}{*}{$\begin{array}{l}\text { Zhuyin } \\
\text { method }\end{array}$} & \multicolumn{5}{|c|}{ Boshiamy input method } \\
\hline & & $\begin{array}{l}\text { The } \\
\text { first test }\end{array}$ & $\begin{array}{l}\text { The } \\
\text { second test }\end{array}$ & $\begin{array}{l}\text { The } \\
\text { third test }\end{array}$ & $\begin{array}{l}\text { The } \\
\text { fourth test }\end{array}$ & $\begin{array}{l}\text { The fifth test } \\
\text { (approximately } \\
4 \text { months after } 4 \text { th) }\end{array}$ \\
\hline $\begin{array}{l}\text { Number of reading } \\
\text { characters }\end{array}$ & 97 & 25 & 30 & 33 & 48 & 101 \\
\hline $\begin{array}{l}\text { Number of correct } \\
\text { characters }\end{array}$ & 66 & 24 & 27 & 30 & 41 & 97 \\
\hline $\begin{array}{l}\text { Typing speed } \\
\text { (characters/minute) }\end{array}$ & 13.2 & 4.8 & 5.4 & 6 & 8.2 & 19.4 \\
\hline Number of typos & 22 & 0 & 1 & 0 & 0 & 4 \\
\hline Typing accuracy rate $(\%)$ & 68.04 & 96.00 & 90.00 & 90.91 & 85.42 & 96.04 \\
\hline
\end{tabular}

Besides pre-test using with subject's original input method, 2 weeks after the instructional course was given, four tests were conducted with Boshiamy input method in an interval of one or two weeks. Then, at the end of 4 months follow-up consultation via e-mails and Skype web phone communications, another test was conducted 
Table 4 Subject B's typing performance

\begin{tabular}{llllllll}
\hline & $\begin{array}{l}\text { Zhuyin } \\
\text { method }\end{array}$ & \multicolumn{6}{l}{ Boshiamy input method } \\
\cline { 5 - 8 } & & $\begin{array}{l}\text { The } \\
\text { first test }\end{array}$ & $\begin{array}{l}\text { The } \\
\text { second test }\end{array}$ & $\begin{array}{l}\text { The } \\
\text { third test }\end{array}$ & $\begin{array}{l}\text { The } \\
\text { latest test }\end{array}$ & $\begin{array}{l}\text { The fifth test } \\
\text { (approximately } \\
\text { 4 months after 4th) }\end{array}$ \\
\hline $\begin{array}{l}\text { Number of reading } \\
\text { characters }\end{array}$ & 138 & 33 & 42 & 69 & 74 & 131 \\
$\begin{array}{c}\text { Number of correct } \\
\text { characters }\end{array}$ & 124 & 18 & 41 & 61 & 70 & 122 \\
$\begin{array}{c}\text { Typing speed } \\
\text { (characters/minute) }\end{array}$ & 24.8 & 3.6 & 8.4 & 12.2 & 14 & 24.4 \\
$\begin{array}{c}\text { Number of typos } \\
\text { Typing accuracy rate }(\%)\end{array}$ & 99.86 & 55 & 98 & 88.41 & 94.59 & 93.12 \\
\hline
\end{tabular}

Besides pre-test using with subject's original input method, 2 weeks after the instructional course was given, four tests were conducted with Boshiamy input method in an interval of one or two weeks. Then, at the end of 4 months follow-up consultation via e-mails and Skype web phone communications, another test was conducted

were inspired by the way how Boshiamy was decoding which they thought interesting and it relatively established the stronger learning motivation and curiosity than others. Not only did they consider typing is a challenging game but also figure out the benefit from using it (such as more accurate and faster). Besides, their parents seem to put a lot of effort on assisting and encouraging them during the instruction.

The adult participants all had fulltime or part-time jobs. For this reason, the amount of time they had to spend on studying the new input method was more limited as compared to that of the children. The observation was consistent with Chen (2013) who indicated that the adult have to readapt a new role as learner besides their original roles. The learning could be ineffective and slower if time and mental adaption were not managed well (Pappas 2013). On the contrary, the children were in school where they could find immediate solutions to the problems they were experiencing and more fundamental material for practicing the new method.

Chinese is a language based on ideographs that provide many visual clues (Kwok $\&$ Chan 2008). Thus, the visual memory of the characters has a major influence on the development of appropriate recognition of Chinese characters (Huang \& Hanley 1995; Chang, 2008). From this perspective, the findings of the present study were consistent with the results of previous studies.

\section{Conclusion}

This study attempted to identify the suitable Chinese typing method for the visually impaired people and then based on the results to use assistive technology to construct an instruction course for blind students to learn entering Chinese character into a computer and to a proper level of literacy in Chinese and evaluate the usefulness of the designed course materials to the target users. 
The results of this preliminarily study indicated that the accuracy rates of Chinese character input for the two subjects were greatly enhanced during the period of this study for half a year. The inspiring and promising results indicate that there is a need for us to further apply this Instructional Design to more visually impaired children in our future study and hope more blind children can benefit from this method and courseware through our long term efforts.

Although it has long been considered meaningless and unnecessary for the blind to learn Chinese characters because of the difficulty and limited applications, the technology nowadays has provided opportunities for the blind to access such information which can increase their social competitiveness in the future. We hope that this pioneering research can inspire related course designers and teachers in blind education and discover more potential possibilities in this field.

\section{Appendices}

Appendix 1 Survey of questionnaire for the satisfaction of using Chinese input methods

In order to understand the satisfaction conditions of using Chinese input methods for the visually impaired in Taiwan, the following questionnaire is prepared for this purpose.

It is designed only for academic research, not for other purposes. You are cordially invited to fill out this questionnaire. Thank you for the assistance.

The questionnaire is divided into two parts, including 14 questions.

\section{Part I: background information's}

1. What is your Age?

2. What is your highest Education Level?
(A) Grade 6 or below (B) Grade 7-9 (C) Grade 10-12 (D) College/university or above

3. What kind of input layouts used for your device?
(A) Braille input
(B) QWERTY Keyboard (C)

(C) tour

4. What is the most commonly used input method
(A) Microsoft new Zhuyin
(B) Going
(C) Boshiamy (D) Cangjie
(E) Others

5. How many years have you been using this input method?

6. What are your commonly used screen readers? (Can be multiple choices)) (Multiple choice)
(A) NVDA (B) g-mouse
(C) big eye/Sunshine (D)
(D) Voiceover
(E) JAWS (F) Others

Part II: satisfaction level

Please answer the following questions according to the agreement of satisfaction level based on your experience, with numbers ranking from 1 to 5 , which is indicated as follows: 
1 Strongly disagree; 2 Disagree; 3 Neither agree nor disagree; 4 Agree; 5 Strongly agree

(1) I think the currently used Chinese input method is easy to learn.

(2) I think the currently used Chinese input method is easy to use.

(3) I think the currently used Chinese input method is easy to select the desired one from the candidate characters if required.

(4) I feel free of pressure on the typos in my typing documents.

(5) I am satisfied on the function of user customization provided by the input method currently used.

(6) I am satisfied on my speed of Chinese typing.

(7) I am satisfied on the accuracy rate of my typing documents.

(8) If there is a more suitable input method for me to use, I am willing to learn it to improve my typing.

Appendix 2 examples of tactile pictogram materials

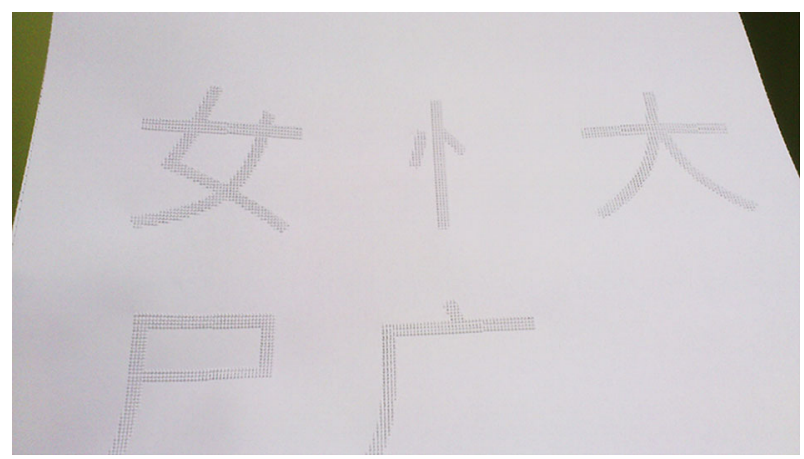

Appendix 3 examples of character descriptions in NVDA file for traditional Chinese

Due to the fact that so many Chinese characters sound the same, it is necessary to provide the function of character description when using screen reader. NVDA has a built-in file which can be configured by the user to meet his need. To announce the character focused, the user can press the number pad keystroke 2 twice. Some examples are listed as follows.

Note: The first row of each example is in Chinese which is adapted from NVDA built-in file, while the second row is conveyed into English with the corresponding Pinyin for each Chinese character and its translation in parenthesis.

一 數字一一定一言九鼎一帆風順 第一名 百聞不如一見

Yī (One) shùzì yī (Number one in Chinese) yī ding (Sure) yī yán jiǔ dǐng (Keep one's promise) yī fān fēng shùn (Smooth sailing) dì yī míng (number one ranking) băi wén bù rú yî jiàn (Seeing is believing) 


\section{上 上午 上司 上將 上學 桌上 地上 不求上進}

Shàng (UP) Shàng wǔ (Morning) Shàng si (Boss) shàng jiàng (Admiral) Shàng xué (Go to school) zhuō shàng (top of table) Dì shàng (Ground) bù qiú shàng jìn (Do not make progress)

中 中央 中間 中秋節 中華 中心點 百發百中

Zhōng (Middle) Zhōng yāng (Center) Zhōng jiān (Middle) Zhōng qiū jié (MidAutumn Festival) Zhōng huá (China) zhōngxīn diăn (Central point) băi fā băi zhòng (Crack shot)

Appendix 4 some examples of commonly used Chinese Characters for Boshiamy File

The file “舆蝦米常用字庫暨字形提要” which contains 4777 commonly used traditional Chinese characters is use as the supplementary self-learning materials. If a learner finds that he forgets or has no idea about the formation of one Chinese character, he can look up this file to get necessary information, such as the description of formation for this character, character description, and its Boshiamy code. Some examples and the corresponding English translations are listed in the following.

0003 七 $=\mathrm{C}$ 數字七 七夕 七寶 七巧板 七零八落; 打禪七三七二十一 七的字形 $=$ (似英文大寫字母L中間加一横, $\mathrm{c}$ 字根)

0003 七 $=\mathrm{C}$ Shù zì qī (Number seven in Chinese) Qī xì (Qixi Festival) Qī băo (Seven precious materials) qī qiăo băn (Tangram) qī líng bā luò (everything broken

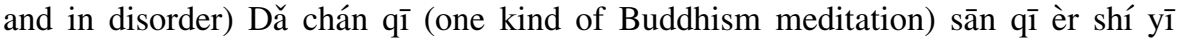
(regardless of the consequences)

$七$ glyph $=$ (like the letter L middle of a cross, c Radicals).

0004 三 $=\mathrm{S}$ 數字三 三思 三字經 三十六計 三陽開泰; 癒三 張三李四

三的字形 $=$ (三橫, $\mathrm{s}$ 的字根)

0004 三 = S Shùzì sān (Number seven in Chinese) sān sī (Think twice) sān zì jīng (three words bible) sān shí liù jì (Thirty-Six Stratagems) Sān yáng kāi tài (The spring comes in full form) biē sān (bad guy) Zhāng sān lǐ sì (mention in some people)

三glyph $=$ (three horizontal, s Radicals).

0005 下 $=\mathrm{FA}$ 下面 下游 下水道 下意識; 天下 樹下 不恥下問

下的字形 $=$ (似英文大寫字母T右下加一點)

0005 下 $=$ FA Xià (Down) Xià miàn (Below) xià yóu (Downstream) xià shuǐ dào (Sewer) xià yì shí (Sub-consciousness) tiān xià (World) shù xià (Under the tree) bù chǐ xià wèn (Always ask questions)

下glyph $=$ (like the letters $\mathrm{T}$ lower right corner to add a dot).

\section{References}

Bustamante, E. A., \& Spain, R. D. (2008). Measurement invariance of the Nasa TLX. In Proceedings of the Human Factors and Ergonomics Society Annual Meeting (Vol. 52, pp. 1522-1526). SAGE Publications. 
Chang, L. F. (2008). A case study on the writing performance of a student with mild mental retardation and writing difficulty. Master's thesis. Department of Special Education, National Taipei University of Education.

Chen, Y. H. (2013). Observation and Assessment of Adult Learning Barriers. National Academy of Civil Service, 132.

Chuang, S. C. (2004). Reading medium assessment for student with low vision: A comparison of largetype materials and computer magnification software. Bulletin of Special Education, 27, 137-160.

Edman, P. K. (1992). Tactile graphics. New York: American Foundation of the Blind.

Ho, F. T. (2012). The impact of frequency and configurational structures on Taiwan elementary school students' character similarity judgment. Master's thesis, National Cheng Kung University, Tainan.

Hsiao, C. H. (2012). The effect on Chinese character instruction for a congenital blind student. Master's thesis, National University of Tainan, Tainan.

Huang, H. S., \& Hanley, J. R. (1995). Phonological awareness and visual skills in learning to read Chinese and English. Cognition, 54, 73-98.

Jiang, Y. J. (2004). Obstacle caused by Chinese braille is without word form concept. Center of Education and Rehabilitation for the Visually Impaired, 51, 10-14.

Kwok, E., \& Chan, L. (2008). Preschool children's visual perception of chinese characters. Journal of Basic Education, 17(1), 59-71.

Leahy, D., \& Lawler, S. (2012). NCBI and digital literacy: A case study. In Computers Helping People with Special Needs, 243-250.

Longcamp, M., Boucard, C., Gilhodes, J. C., \& Velay, J. L. (2006). Remembering the orientation of newly learned characters depends on the associated writing knowledge: A comparison between handwriting and typing. Human Movement Science, 25, 646-656.

Marcia, L. W., Kenneth, P., \& Barbara, C. (1999). Distance learning: The essential guide. Thousand Oaks: Sage.

Ministry of Education (2014). Statistics domestic students with disabilities, from http://www. set.edu.tw/sta2/frame_print.asp?filename=stuA_city_All_spckind_BC/stuA_city_All_spckind_BC_ 20140528.asp.

Ministry of Health and Welfare (2014). Domestic handicapped people counting, from http://www.mohw. gov.tw/cht/DOS/DisplayStatisticFile.aspx?d=31864\&s=1.

Murata T. (2004). Han language and Chinese Braille, Retrieved January 13, 2014, from http:// murata-cjr.info/?page_id=94.

NASA (2003). NASA task load index (TLX): Computerized Version (Version 2.0) [Computer Software]. Moffett Field, CA: NASA-Ames Research Center.

Pappas, C. (2013). 8 important characteristics of adult learners. Retrieved May 21, 2014 from http://elearningindustry.com/8-important-characteristics-of-adult-learners.

Pollster (2011). Taiwanese typist input method survey 2011, Pollster On-line Survey, Retrieved January 25, 2014, from http://www.pollster.com.tw/Aboutlook/lookview_item.aspx?ms_sn=1476.

Wang, J. L., Hwang S. L., \& Lin, J. H. (2011). Investigation of digital learning by using NVDA for visually impaired students. Published in the 7th Taiwan E-Learning Forum, Taipei.

Wang, J. L., Weng, T. H., Hwang, S. L., Young, S. C., \& Lai, Y. C. (2014). A preliminary study on using assistive technologies to construct a digital learning system for congenital blind students to learn Chinese input method. Proceedings of 18th Global Chinese Conference on Computers in Education (GCCCE 2014). Shanghai, China.

Wikipedia (2014a). Chinese character classification. Retrieved January 13, 2014, from http://en. wikipedia.org/wiki/Chinese_character_classification. Besides of this.

Wikipedia (2014b). Cangjie input method. Retrieved January 17, 2014, from http://en.wikipedia. org/wiki/Cangjie_input_methodo.

Wikipedia (2014c). Bopomofo. Retrieved January 17, 2014, from http://en.wikipedia.org/wiki/Bopomofo. Wikipedia (2014d). Boshiamy method. Retrieved January 17, 2014, from http://en.wikipedia.org/ wiki/Boshiamy_method.

Jan-Li Wang is a Research Fellow, and his area of research interest includes the development and applications of assistive technology for the visually impaired people. 
Teng-Hua Weng is a graduate student, and his areas of research interest include assistive technology and man-machine interface system.

Sheue-Ling Hwang is a retired full professor, and her areas of research interest include Ergonomics and man-machine interface System.

Cin-Wei Huang is a graduate student, and his research areas include assistive technology and web-based learning system.

Shwu-ching Young is a full professor and her areas of research interestinclude instructional design, information technology in teacher education and higher education, E-learning and lifelong education and web-based learning community, interactive multimedia design, and computer-supported collaborative learning. 